\title{
A meta-analysis of global stillbirth rates during the COVID-19 pandemic.
}

\author{
Manoj Mohan ${ }^{1}$, Kwabena Appiah-Sakyi ${ }^{2}$, Ashok Oliparambil ${ }^{3}$, Abdul Pullatayil ${ }^{3}$, \\ Stephen Lindow ${ }^{4}$, and Justin Konje (TOG CPDs) ${ }^{5}$ \\ ${ }^{1}$ Aster DM Healthcare, Qatar \\ ${ }^{2}$ Britannia Medical Centre \\ ${ }^{3}$ Sidra Medicine \\ ${ }^{4}$ Coombe Women and Infants University Hospital \\ ${ }^{5}$ University of Leicester
}

June 23, 2021

\begin{abstract}
Background The global effect of the COVID-19 pandemic has had an impact on pregnancy and outcomes. There has been recently some conflicting evidence on the stillbirths during the COVID-19 pandemic. This meta-analysis attempts to resolve this through a systematic approach. Objectives To analyse and determine the impact of COVID-19 on the stillbirth rate. Search strategy We searched PubMed, Embase, Cochrane library, ClinicalTrials.gov and Web of Science from inception to 05 March 2021 with no language restriction for this meta-analysis. Selection criteria Publications (a) with stillbirth data on pregnant women with COVID-19 (b) comparing stillbirth rates in pregnant women with and without COVID-19 and (c), comparing stillbirth rates before and during the pandemic. Data collection and Analysis The included studies were all observational studies, and we used the Newcastle Ottawa score for risk of bias. We performed the meta-analysis using Comprehensive metaanalysis software, version 3. Main results A total of 29 studies were included in the meta-analysis; from 17 of these, the SB rate was 7 per 1000 in pregnant women with COVID-19. This rate was much higher (34/1000) in low- and middle-income countries. The odds ratio of stillbirth in pregnant women with COVID-19 compared to those without was 1.89. However, there was no significant difference in population SB rates before and during the pandemic. Conclusions There is some evidence that the stillbirth rate has increased during the COVID-19 pandemic, but this is mainly in low- and middle-income countries. Inadequate access to healthcare during the pandemic could be a contributing factor.
\end{abstract}

\section{Hosted file}

Main document.pdf available at https://authorea.com/users/421241/articles/527353-a-metaanalysis-of-global-stillbirth-rates-during-the-covid-19-pandemic

\section{Hosted file}

Figure 1.docx available at https://authorea.com/users/421241/articles/527353-a-metaanalysis-of-global-stillbirth-rates-during-the-covid-19-pandemic

\section{Hosted file}

Figure 2.docx available at https://authorea.com/users/421241/articles/527353-a-metaanalysis-of-global-stillbirth-rates-during-the-covid-19-pandemic

\section{Hosted file}


Figure 3.docx available at https://authorea.com/users/421241/articles/527353-a-metaanalysis-of-global-stillbirth-rates-during-the-covid-19-pandemic

\section{Hosted file}

Figure 4.docx available at https://authorea.com/users/421241/articles/527353-a-metaanalysis-of-global-stillbirth-rates-during-the-covid-19-pandemic 